\title{
The role of $\mathrm{p53}$ in the chemotherapeutic responses to cisplatin, doxorubicin and 5-fluorouracil treatment
}

\author{
D. ALWYN DART ${ }^{1}$, STEVEN M. PICKSLEY ${ }^{2}$, PATRICIA A. COOPER ${ }^{1}$, \\ JOHN A. DOUBLE ${ }^{1}$ and MICHAEL C. BIBBY ${ }^{1}$ \\ ${ }^{1}$ Cancer Research Unit, ${ }^{2}$ Department of Biomedical Sciences, University of Bradford, Bradford BD7 1DP, UK
}

Received May 5, 2003; Accepted July 2, 2003

\begin{abstract}
A panel of tumour models used extensively for in vivo evaluation of new drugs was characterised for their p53 status. Basal p53 protein levels were measured by immunodetection on both formalin-fixed tumour tissue and from protein extracts of fresh tumours. High levels of nuclearspecific staining, indicative of p53 mutation, was seen in $15 / 25$ tumours, with the remainder showing intermittent or no staining. The functional status of p53 cDNA from these tumours was assayed within the functional analysis of separated alleles in yeast (F.A.S.A.Y.) reporter system. The cDNA from those tumours with high levels of $\mathrm{p} 53$ protein showed $14 / 15$ failing to activate the reporter gene. The cDNA from tumours with low or non-detectable p53 levels showed $8 / 10$ with wild-type p53. Tumours were grown subcutaneously in mice $(n=10)$. Each mouse was given maximum tolerated doses for either doxorubicin, 5-fluorouracil or cisplatin. Tumour volumes were measured daily, alongside untreated controls. The specific growth delay values for each tumour were separated into two groups, those with functional p53 (wild-type) and those without (mutant and null status). The Mann-Whitney U test was performed on the groups of data, to evaluate differences in their response on the basis of p53 status. Cisplatin was moderately active against tumours with wild-type and mutant p53 genes with no significant difference seen between both groups. However, a significant difference in specific growth delay was seen between the two groups when treated with doxorubicin or 5-fluorouracil $(\mathrm{P}=0.05)$, indicating a role for $\mathrm{p} 53$ protein in modulating the in vivo efficacy of these agents.
\end{abstract}

\section{Introduction}

Mammalian cells respond to DNA damage by activating cell cycle checkpoints that arrest the cell cycle at specific points

Correspondence to: Professor M.C. Bibby, Cancer Research Unit, University of Bradford, Bradford BD7 1DP, UK E-mail: cru@bradford.ac.uk

Key words: p53; chemotherapy response; preclinical models to allow DNA repair. P53 is a nuclear phosphoprotein that functions as a sequence specific transcription factor. P53 protein is involved in cell cycle control, DNA repair, apoptosis, cellular differentiation and senescence (1). P53 regulates the G1 checkpoint $(2,3)$, where DNA damage activates p53 protein leading to transactivation of the cyclin-dependent kinase inhibitor p21 WAF $(4)$. Irrepairable DNA damage can trigger p53-dependent apoptotic pathways within the cell involving several p53-transactivated proteins e.g. bax (5), Fas/APO-1 (6), and many redox related genes (7). The lack of a functioning p53 may lead to the maintenance of cells with damaged DNA, from which genetic instability can occur. P53, therefore, preserves genome integrity and has been described as being the 'guardian of the genome' (8).

Many of the chemotherapy agents used in the clinic have mechanisms that rely specifically on interaction with DNA. DNA damage will cause cell cycle arrest or apoptosis within these cells resulting in inhibition of tumour growth. One of the main pathways activated in response to DNA damage, being the activation of $\mathrm{p} 53$ protein. However, the p 53 gene is found to be mutated in over half of all human cancers (9) and as a result, cells with p53 mutations may become resistant to these agents requiring changes in prognostic clinical parameters and treatment choices within the clinic.

Many methodologies are available for the analysis of $\mathrm{p} 53$ gene alterations. In normal cells p53 has a short half-life and a rapid turnover (10). The mutant protein, however, has a greater stability and a longer half-life, causing accumulation of the protein within the nucleus. Immunodetection of increased $\mathrm{p} 53$ protein levels within tumour sections forms the basis of a screening technique that gives a generally good correlation (11). However, the disadvantages of this technique include the failure to distinguish between wild-type and null p53 status and also in revealing tumours with a heterozygous genotype.

The p53 gene therefore requires a more precise analysis tool in order to fully characterise those tumours with dysfunctional p53. Direct DNA sequencing of the gene or cDNA would reveal all mutations, however, this is beyond the scope of many clinical laboratories and is too expensive for routine diagnostics. In this report the functional analysis of separated alleles in yeast (F.A.S.A.Y.) has been utilised (12-14). This reveals whether the p53 cDNA can encode for a functional p53 protein and identifies any tumours with heterozygous genotypes. 
In many clinical studies, p53 mutation has been correlated with poor prognosis and shortened patient survival, especially studies in breast cancer (15). However, clinical biopsy samples are frequently characterised by immunodetection techniques alone that determine p 53 mutation indirectly, and also primary tumours may display field clonality changes as p53 mutant clones appear from previously wild-type cells within a heterogeneous tumour environment during the course of the disease. The variables with such studies are multiple. P53 has not been shown to be a strong enough prognostic marker to be used in routine decision making for chemotherapy. The apparent failure of these studies may be due to many factors including the lack of suitable characterisation of patient tumours, lack of suitable controls e.g. untreated controls, lack of normalisation of dosing schedules and choices.

Characterization of models used for drug development is important in determining targets and sensitivity modulators that may affect drug activity. The NCI cell line panel, used for the screening of anti-cancer compounds, previously showed a close correlation between cell line p53 status and chemosensitivity in vitro to certain chemotherapy agents (16). However, the in vitro setting is far removed from the more clinically relevant in vivo tumour models, as pharmacokinetic, pharmacodynamic and immunological effects are taken into account. Taking a step back from the clinic and examining the role of p53 within well-defined tumour models offers a more controlled setting than the clinical environment for treatment choices and controls and offers a significantly better realistic setting than that found in vitro. A well characterised panel of tumour models would therefore also be a more efficient and ethical tool for further in vivo testing of novel compounds.

Here we report the characterisation of a panel of tumours, both human and murine, and their sensitivities to three agents used in the clinic, 5-fluorouracil, doxorubicin and cisplatin. These tumours represent useful tumour models with varying degrees of tissue type, differentiation, chemosensitivity, growth rates and aggressiveness. These three agents exert their cytotoxic activities through DNA interacting mechanisms and, as a result, the status of $\mathrm{p} 53$ within these tumours may have a profound effect on how they respond to these agents. The aims of this study were to determine whether p53 status alone does indeed modulate the sensitivity of tumours to these DNA damaging agents and to examine whether such correlations can be made within a more controlled tumour model environment, because if not, the hope of drawing such correlations within patients may be impossible.

\section{Materials and methods}

Tumours. Tumours grown subcutaneously were excised from mice and cut up into smaller pieces. Small tumour pieces were then implanted subcutaneously in mice using a trocar and allowed to grow until they reached a sufficient size. The procedure was performed under a project licence approved by the Home Office, London and U.K.C.C.C.R. official guidelines (17) were followed throughout. Tumour types and sources can be seen in Table I.

Immunostaining for p53 overexpression. Formalin-fixed paraffin-embedded tumour tissue was cut at $6 \mathrm{~mm}$ thickness.
Table I. The types and sources of the tumours used in the study.

\begin{tabular}{ll}
\hline Name & \multicolumn{1}{c}{ Tumour type } \\
\hline F9 & Mouse testicular carcinoma (18) \\
MAC13 & Mouse adenocarcinoma of the colon (19) \\
MAC15 & Mouse adenocarcinoma of the colon (19) \\
MAC15A & Ascites cells of MAC15 (20) \\
MAC16 & Mouse adenocarcinoma of the colon (21) \\
MAC26 & Mouse adenocarcinoma of the colon (21) \\
MAC29 & Mouse adenocarcinoma of the colon (21) \\
MAC30T & Mouse adenocarcinoma of the colon (22) \\
MAC31 & Mouse adenocarcinoma of the colon (21) \\
MAC32 & Mouse adenocarcinoma of the colon (21) \\
COLO205 & Human colon adenocarcinoma (23) \\
DLD-1 & Human colon adenocarcinoma (24) \\
HT29 & Human colon adenocarcinoma (25) \\
HCC2998 & Human colon adenocarcinoma \\
HCT116 p53 ${ }^{+/+}$ & (from NCI, original reference not given) \\
HCT116 p53 $\%$ & Human colon adenocarcinoma (26) \\
SW620 & p53 knock out (27) \\
H460 & Human colon adenocarcinoma (28) \\
H69 & Human lung carcinoma (29) \\
MT-1 & Human lung carcinoma (29) \\
MCF-7N & Human mammary carcinoma \\
NCI ADR & (30 and refs. therein) \\
MT-3 & Human mammary carcinoma (31) \\
Adriamycin resistant cell line
\end{tabular}

The sections were dewaxed in xylene and rehydrated through a series of alcohol (100-70\%) and finally into distilled water. After washing in distilled water and then PBS (phosphate-buffered saline, $\mathrm{pH}$ 7.6) the sections were immersed for $15 \mathrm{~min}$ in $1 \% \mathrm{H}_{2} \mathrm{O}_{2}$ in $\mathrm{PBS}$, to quench any endogenous peroxidase activity. Following another $10 \mathrm{~min}$ wash in PBS the sections were immersed in $10 \mathrm{mM}$ citric acid monohydrate buffer ( $\mathrm{pH} 6.0$ ), and microwaved for $5 \times 5$ $\min (750 \mathrm{~W})$ for antigen retrieval, ensuring that they were completely immersed in buffer throughout each microwaving treatment. Following microwaving the sections were allowed to cool to room temperature and were then transferred to PBS ( $\mathrm{pH} 7.6)$ and washed for $5 \mathrm{~min}$. All subsequent incubations were performed in PBS and carried out in a humidified chamber to prevent dehydration. Sections were then blocked using normal serum (Vector, Peterborough, U.K.) for 30 min. The p53 protein was detected by using either DO- 1 mouse anti-human p53 monoclonal antibody (for human tumour sections) or CM-5 rabbit anti-mouse p53 polyclonal 
antibody (for mouse sections) both from Novocastra (Newcastle upon Tyne, U.K.). The Vectastain ABC kit (Avidin-Biotin Complex using horseradish peroxidase) obtained from Vector, was used for the detection of the primary antibodies, used at manufacturer's recommendations, using diaminobenzidine as the chromogenic substrate. The sections were counterstained with haematoxylin. After dehydration the sections were mounted in DPX and examined.

Protein extraction from tumours. Whole tumours or tumour samples were collected from mice with subcutaneously implanted tumours during a routine passaging procedure. The tumours were immediately frozen in liquid nitrogen. The tissue was then sonicated on ice using a Semat 250 sonicator (Semat, St. Albans, UK), in the presence of protease inhibitors, at a maximum setting of 7 microns with $5 \times 5 \mathrm{sec}$ bursts to extract the protein.

SDS-PAGE of protein samples. Samples, containing $30 \mu \mathrm{g}$ of protein, were loaded onto a polyacrylamide gel consisting of a $4 \%$ stacking gel and a $10 \%$ resolving gel. Proteins were then transferred to a nitrocellulose membrane by electroblotting apparatus.

Western blotting. Non-specific protein binding was blocked by adding a solution of TBS (Tris-buffered saline) with Tween-20 (0.05\%) containing 5\% w/v non-fat dried milk. This was incubated with gentle agitation at room temp for $1 \mathrm{~h}$. The membranes were then probed with DO-1, or CM-5, for $1 \mathrm{~h}$ at room temperature. The membrane was incubated with a 1/2500 dilution of secondary HRP labelled antibody (Roche, Welwyn Garden City, UK) in blocking solution for at least 30 min, followed by thorough washes in TBS-Tween-20 (0.05\%). The membrane was then incubated in chemiluminescent substrate (ECL from Amersham Pharmacia Biotech, Little Chalfont, UK) for $1 \mathrm{~min}$ and light emission was captured using ECL hyperfilm (Amersham), developed according to the manufacturer's recommendations. Membranes were then stripped and reprobed with an anti- $\beta$-actin antibody (Sigma) to determine equal loading.

RNA extraction and $c D N A$ synthesis. Tissue samples were removed from mice with subcutaneous tumours during routine passaging and were immediately frozen in liquid nitrogen. Total RNA was purified using the Purescript RNA isolation kit (Gentra Systems, Minneapolis, USA), from between 5-10 mg of tissue ground with a microfuge pestle. The quality of the RNA was visually estimated by the presence of the $18 \mathrm{~S}$ and 28S rRNA bands upon electrophoresis with ethidium bromide stain.

The RNA was reverse transcribed, using AMV (Avian myeloblastosis virus) reverse transcriptase (Roche, Welwyn Garden City, UK), into single stranded cDNA using an oligo$\mathrm{p}(\mathrm{dT})$ primer to select for poly $(\mathrm{A}) \mathrm{mRNA}$. The reaction was incubated at $25^{\circ} \mathrm{C}$ for $10 \mathrm{~min}$ to allow the primer to anneal and then at $42^{\circ} \mathrm{C}$ for $60 \mathrm{~min}$ for reverse transcription. To minimise interference with subsequent applications, the AMV reverse transcriptase was then denatured by heating at $99^{\circ} \mathrm{C}$ for $5 \mathrm{~min}$. The reaction products were stored at $-80^{\circ} \mathrm{C}$.
Amplification of p53 cDNA by PCR. The p53 cDNA was amplified by PCR using the following primers (Oswell, Southampton, UK). Human specific primers (13). Sense 5'ATT-TGA-TGC-TGT-CCC-CGG-ACG-ATA-TTG-AA(S)C3' Antisense 5'-ACC-CTT-TTT-GGA-CTT-CAG-GTG-GCTGGA-GT(S)G-3'. Mouse specific primers Sense 5'-ATCTGT-TGC-TGC-CCC-AGG-ATG-TTG-AGG-AG(S)T-3' Antisense 5'-ACC-CTT-TTT-GGA-CTT-CAG-GTG-GCTGGA-GT(S)G-3'. Where (S) represents a phosphorothioate linkage.

PCR was performed for 35 cycles of $94^{\circ} \mathrm{C}$ for $30 \mathrm{sec}$, $65^{\circ} \mathrm{C}$ for $60 \mathrm{sec}$ and $78^{\circ} \mathrm{C}$ for $80 \mathrm{sec}$ using a thermal cycler that had been preheated to $95^{\circ} \mathrm{C}$. The PCR mix was allowed a final extension at $74^{\circ} \mathrm{C}$. $2 \mu \mathrm{l}$ of the cDNA reaction product was amplified in $20 \mu \mathrm{l}$ of $P f u$ buffer (Promega, Southampton, UK) plus 1.25 units of $P f u$ DNA polymerase, $100 \mathrm{ng}$ of primers, $10 \%$ dimethyl sulphoxide, and $50 \mu \mathrm{M}$ dNTPs. PCR controls included (i) negative control incubation without template DNA and (ii) positive controls included plasmids known to contain the $533 \mathrm{cDNA}$ sequence.

PCR reaction product $(5 \mu \mathrm{l})$ was then run on a $1.5 \%$ agarose gel, alongside a molecular weight marker, to check the PCR product.

Vector preparation for transformation of yeast. The plasmid pSS16 (13) was obtained from Dr R. Iggo (I.S.R.E.C. Switzerland). $5 \mu \mathrm{l}$ of plasmid ( $10 \mu \mathrm{g}$ approx) was cut by restriction digest using Stul and HindIII. The linearised vector was then dephosphorylated using calf intestinal alkaline phosphatase (Sigma-Aldrich Company Ltd. Dorset, $\mathrm{UK}$ ) at $37^{\circ} \mathrm{C}$ for $30 \mathrm{~min}$. The linearised vector was gel purified using the Glassmax DNA isolation kit (Invitrogen, Paisley, UK) and redissolved in TE buffer ( $\mathrm{pH}$ 8.3).

Yeast transformation and growth. The yeast strain yIG397 was obtained from Dr R. Iggo (I.S.R.E.C. Switzerland) and was routinely cultured on complete medium (yeast extract, peptone, dextrose: YPD), supplemented with adenine at $10 \mathrm{x}$ excess concentration $(200 \mu \mathrm{g} / \mathrm{ml})$, to avoid selection of spontaneous suppressors of the endogenous ade 2 locus. The resulting colonies were all white in colour. Any red colonies would have been discarded (13).

Transformation of competent cells. The EasyComp S.c. transformation kit (Invitrogen, Paisley, UK) was used to make the yeast competent, and was also used for the transformation. Linearised vector DNA $(5 \mu \mathrm{l}$ or $1 \mu \mathrm{g})$ and $5 \mu \mathrm{l}$ of PCR product was used for the transformation. The components were mixed by vortexing vigorously. The cells were then incubated for $1 \mathrm{~h}$ at $30^{\circ} \mathrm{C}$, and again vortexed at $15 \mathrm{~min}$ intervals during the incubation. Cells $(100 \mu \mathrm{l})$ were plated on synthetic minimal media minus leucine, left to grow for $2-4$ days at $30^{\circ} \mathrm{C}$, and the number and colour of the yeast colonies were counted.

Control transfections included transfection with linear vector only, pSS16 whole vector only, PCR product only. Untransfected cells were also grown on leucine plus and leucine minus media. PCR products from plasmids with known p53 status i.e. wild-type and known mutants were also transfected. 

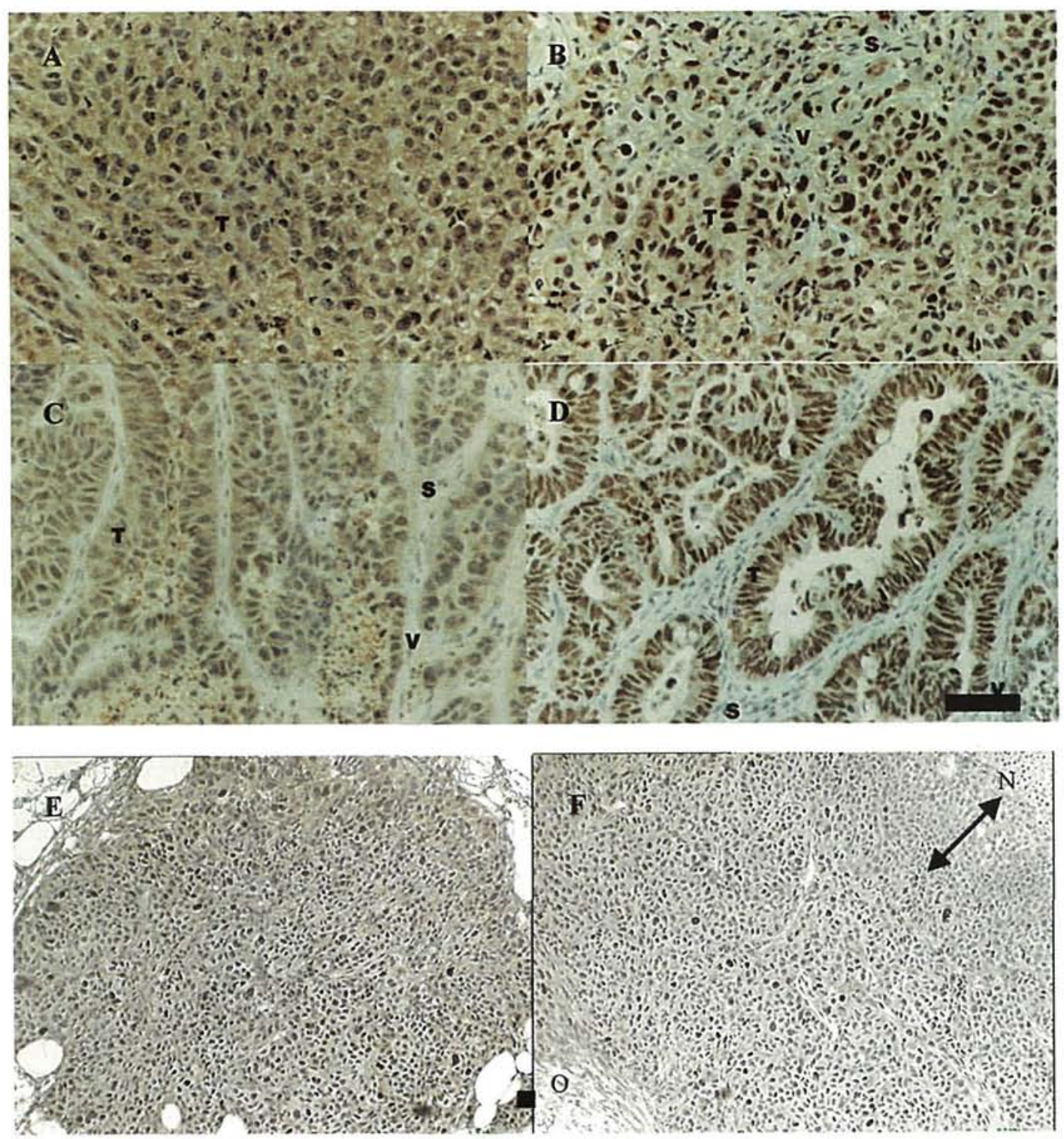

Figure 1. Sections of tumour tissue immunostained for p53. A, weak or absent staining in the MT-1 tumour; B, strong nuclear-specific staining seen in the COLO205 tumour; C, weak staining seen in the MAC15 tumour and D, strong nuclear-specific staining seen in the MAC32 tumour (s, stroma; t, tumour; $v$, blood vessel). Bar represents $50 \mu \mathrm{m}$. Immunostaining for p53 in the HCT116 p53 $3^{+/+}$tumour 24 hours after treatment with doxorubicin $(10 \mathrm{mg} / \mathrm{kg})$. E, represents a small tumour nodule showing the absence of a necrotic centre and an uniform distribution of nuclei staining for $\mathrm{p} 53$. F, represents a larger tumour, with a necrotic centre $(\mathrm{N})$ and an area of surrounding cells showing no staining for $\mathrm{p} 53$, indicated with the arrow. $\mathrm{O}$, indicates the outside edge of the tumour showing host skin cells and adipocytes.

In vivo chemotherapy studies. Female NCR-Nu mice (NCI, Frederick, USA) for human tumours and NMRI pure strain mice (B\&K, Hull, UK) for murine tumours aged 6-8 weeks were used for this study. Mice were kept in isolators at $23^{\circ} \mathrm{C}$, under conditions of regular cycles of light and dark and given food (Standard rat and mouse feed from B\&K, Hull, UK) and water, ad libitum. Experiments were performed under a project licence approved by the Home Office, London and U.K.C.C.C.R. official guidelines (17) were followed throughout.

Tumours were grown subcutaneously in mice, and were ready for treatment when their diameters reached 2-4 $\mathrm{mm}$. Mice were separated into treatment and control groups, each made up of 6-12 mice. Single dose drug treatments were given at predetermined maximum tolerated doses, (doxorubicin at $10 \mathrm{mg} / \mathrm{kg}$, cisplatin at $6 \mathrm{mg} / \mathrm{kg}$ and $5-$ fluorouracil at $125 \mathrm{mg} / \mathrm{kg}$ ). Agents were dissolved in sterile saline and administered by intraperitoneal injection (IP) at their maximally tolerated doses. Control groups were injected IP with saline only.

Tumours were measured at daily intervals using calipers and the tumour volume calculated using the formula for the volume of an ellipsoid, where a is equal to the smaller tumour diameter and $\mathrm{b}$ equal to the larger one.

$$
\frac{a^{2} \times b}{2}=\text { Tumour volume }
$$

Relative tumour volume (RTV) for day 0 was given a value of 1. RTV for subsequent days was calculated by comparing 
Table II. Summary of the characterisation data, including the immunodetection of protein levels and F.A.S.A.Y. functional analysis results for each tumour type.

\begin{tabular}{|c|c|c|c|c|c|}
\hline Name & Tumor type & $\begin{array}{l}\text { Immunostaining } \\
\text { description }\end{array}$ & $\begin{array}{l}\text { Band present } \\
\text { on Western blot }\end{array}$ & $\begin{array}{c}\text { Functional } \\
\text { p53 }\end{array}$ & Status \\
\hline F9 & Mouse testicular carcinoma & +ve, nuclear specific & Yes & Yes & WT \\
\hline MAC 13 & Mouse adenocarcinoma of the colon & +ve, nuclear specific & Yes & No & MUT \\
\hline MAC $15 A$ & Mouse adenocarcinoma of the colon & -ve staining & No & Yes & WT \\
\hline MAC 15 & Mouse adenocarcinoma of the colon & -ve staining & No & Yes & WT \\
\hline MAC 16 & Mouse adenocarcinoma of the colon & +ve, nuclear specific & Yes & No & MUT \\
\hline MAC 26 & Mouse adenocarcinoma of the colon & -ve staining & Weak & Yes & WT \\
\hline MAC 29 & Mouse adenocarcinoma of the colon & +ve, nuclear specific & Yes & No & MUT \\
\hline MAC 30T & Mouse adenocarcinoma of the colon & +ve, nuclear specific & Yes & No & MUT \\
\hline MAC 31 & Mouse adenocarcinoma of the colon & +ve, nuclear specific & Yes & No & MUT \\
\hline MAC 32 & Mouse adenocarcinoma of the colon & +ve, nuclear specific & Yes & No & MUT \\
\hline COLO 205 & Human colon adenocarcinoma & +ve, nuclear specific & Yes & No & MUT \\
\hline HCC2998 & Human colon adenocarcinoma & -ve staining & No & No & MUT/NULL \\
\hline HCT 116 & Human colon adenocarcinoma & -ve staining & No & Yes & WT \\
\hline HCT $116 \mathrm{p} 53^{-/}$ & Human colon adenocarcinoma & -ve staining & No & NA / null & NULL \\
\hline SW620 & Human colon adenocarcinoma & +ve, nuclear specific & Yes & No & MUT \\
\hline DLD-1 & Human colon adenocarcinoma & +ve, nuclear specific & Yes & No & MUT \\
\hline HT29 & Human colon adenocarcinoma & $+v e$, nuclear specific & Yes & No & MUT \\
\hline A431 & Epidermoid-squamous carcinoma & +ve, nuclear specific & Yes & No & MUT \\
\hline U87-MG & Human glioblastoma-astrocytoma & -ve staining & No & Yes & WT \\
\hline $\mathrm{H} 460$ & Human lung carcinoma & -ve staining & No & Yes & WT \\
\hline MT-1 & Human mammary carcinoma & -ve staining & No & Yes & WT \\
\hline MT-3 & Human mammary carcinoma & Intermittent staining & Yes & Heterozygous & WT/MUT \\
\hline MCF-7N & Human mammary carcinoma & -ve staining & No & Yes & WT \\
\hline NCI ADR ${ }^{R}$ & Human mammary carcinoma & +ve, nuclear specific & Yes & No & MUT \\
\hline MDA-MB-435 & Human mammary carcinoma & +ve, nuclear specific & Yes & No & MUT \\
\hline
\end{tabular}

the tumour volume to the volume on day 0 . The time taken for the tumour volume to double, RTV 2 was calculated and the significance of any delays in tumour growth between mean values of the control and treated groups was determined by use of the Mann-Whitney U-test.

Correlation between p53 status and the growth delay observed with the standard agents - statistical analysis. The specific growth delay (SGD) for each treated tumour was measured using the following formula, where T'2 is the time taken for the treated tumour to double, and the T2 is the time taken for the (untreated) control to double in volume (36).

$$
\mathrm{SGD}=\frac{\mathrm{T}^{\prime} 2-\mathrm{T} 2}{\mathrm{~T}^{\prime} 2}
$$

This allowed the responsiveness of a panel of tumours which differ in growth rate, to be compared. The tumour lines were separated into two groups; wild-type and mutant. The statistical significance between the mean specific growth delay for both groups was then determined by the MannWhitney U-test using SPSS software.

\section{Results}

Immunodetection of protein levels. Basal levels of the p53 protein were determined from formalin-fixed tumour tissue sections and also from protein extracts from fresh tumour tissue, using the DO- 1 and CM-5 antibodies. Three basic patterns of immunostaining were observed, i) strong nuclearspecific staining, ii) weak staining in some nuclei, and iii) no detectable protein. Fig. 1A-D gives examples of the types of staining patterns observed, from both human and murine tumours. Normal, i.e. wild-type, background levels of p53 protein was not detected using the titres used here, as shown in the non-staining host tissues e.g. endothelial cells, skin cells etc. The results are summarised in Table II.

The Western blot analysis complemented the immunostaining results and gave a clear band of $53 \mathrm{kDa}$ (approx). An extract from $E$. coli transfected with a human p53 


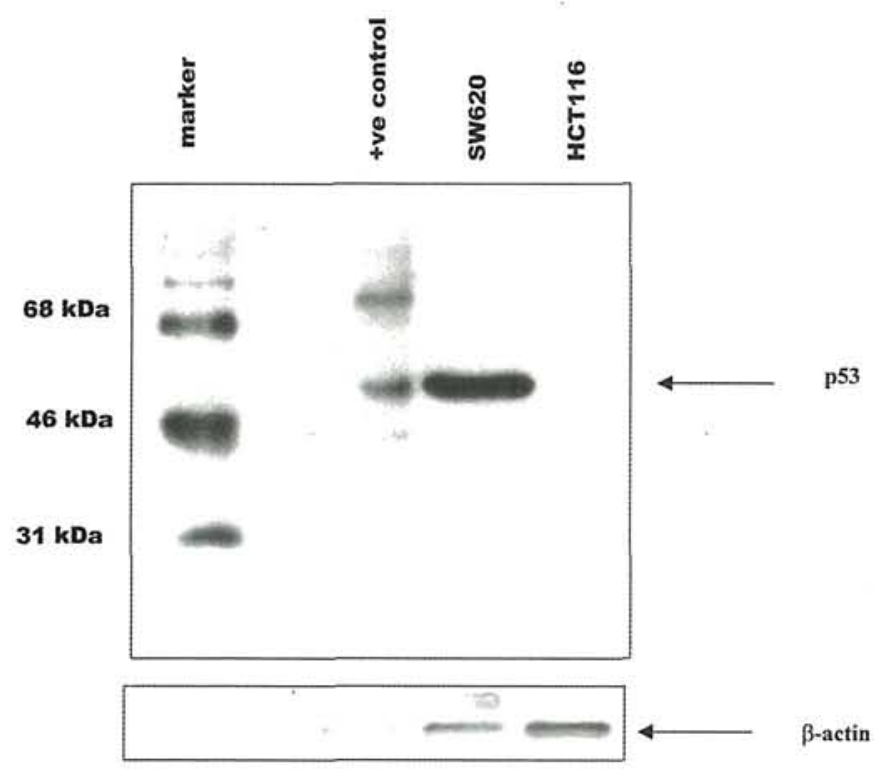

Figure 2. An example of the Western blot analysis done on protein extracts from fresh tumour tissue. The positive control included transfected $E$. coli cells expressing human p53 from a p53 expression construct. A clear single band is seen for p53 from the SW620 tumour whilst the HCT116 tumour did not produce a band for $\mathrm{p} 53$, from an equal loading of $30 \mu \mathrm{g}$ of protein.

expression construct, was used as a positive control. A clear band was seen for $15 / 25$ tumours with the remainder showing very weak bands or no detectable protein. Fig. 2 illustrates an example of the Western blot analysis. The results are summarised in Table II. $\beta$-actin levels did not fluctuate between the tumour types.

Tumours were separated into two groups according to the levels of p53 protein, i) those with high levels of protein and ii) those with low or undetectable levels and $15 / 25$ were classed as having overexpression of $\mathrm{p} 53$ protein.
P53 Functional Assay (F.A.S.A.Y.). Ade2-cells grown on medium containing limiting adenine turn red because of an accumulation of an adenine metabolic intermediate (13). The yeast strain yIG397 contains a plasmid with the ade 2 gene under the control of a p53 promoter. When the yeast is transfected with the cDNA from a wild-type p53 gene, the yeast cells express ade 2 , and grow normally as white colonies on minimal synthetic defined agar. Cells transfected with the cDNA from a mutant tumour, fail to transactivate the ade 2 gene and grow to form red colonies. Plasmids containing wild-type and mutant p53 cDNA sequences were used as controls for the assay. These gave approximately 600 colonies per plate. The cDNA from the tumours gave a lower transformation efficiency of approximately 400 colonies per plate. A small percentage of white colonies was seen amongst the mutant plates, and a small percentage of red colonies was seen amongst the white wild-type colonies. The percentage of yeasts transfected with-wild-type cDNA gave 95\% white colonies and yeasts transfected with mutant cDNA gave $99 \%$ red colonies. Numbers were sufficiently high as not to be significantly affected by the small percentage of differently coloured colonies presumably caused by a small percentage of wild-type host cells. Of the 25 tumours 14 showed non-functional p53 cDNA, with $1 / 25$ being heterozygous, $1 / 25$ known to be null (HCT116 p53\%) and the remainder having functional p53 cDNA. The results are summarised in Table II, and examples of the yeast colonies obtained from both wild-type and mutant tumours can be seen in Fig. 3.

In vivo studies. We investigated whether p53 status could explain the differences in the sensitivity of the panel of tumours used at this laboratory, to the standard chemotherapeutic agents 5-fluorouracil, doxorubicin and cisplatin with respect to their vehicle treated control. A summary of the data is given in Table III. The mean specific growth delay (SGD) response of the tumours to each agent was plotted and separated

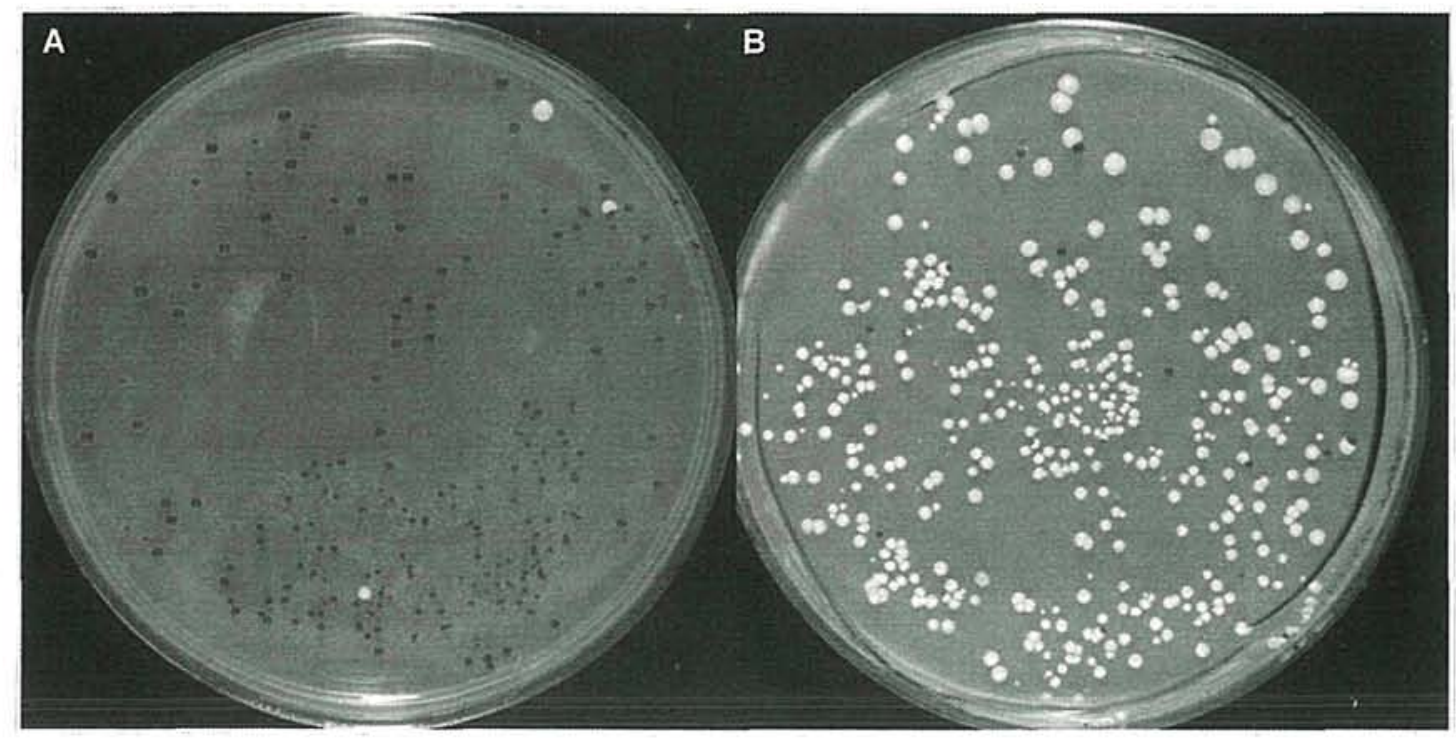

Figure 3. Results of the F.A.S.A.Y. analysis of tumour cDNA. A, yeasts transfected with the cDNA from the COLO205 tumour, showing non-functional p53 and red colonies. B, yeasts transfected with the cDNA from the HCT116 tumour, showing functional p53 and white colonies. 
Table III. Summary of the response of tumours to the maximum tolerated doses of the agents 5-fluorouracil, doxorubicin and cisplatin as compared to their untreated controls. The results represent the mean values from $n=10-12$ tumours indicating doubling times, growth delay, specific growth delays for each tumour type.

\begin{tabular}{|c|c|c|c|c|}
\hline Tumour cell line & $\begin{array}{l}\text { Mean doubling time. } \\
\text { (days) of untreated tumours }\end{array}$ & $\begin{array}{l}\text { Mean doubling time } \\
\text { (days) of treated tumours }\end{array}$ & $\begin{array}{l}\text { Mean growth } \\
\text { delay (days) }\end{array}$ & $\begin{array}{c}\text { Mean specific growth } \\
\text { delay (days) }\end{array}$ \\
\hline \multicolumn{5}{|l|}{ Doxorubicin } \\
\hline DLD-1 & ! & 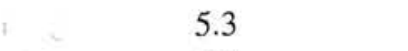 & 0.4 & 0.08 \\
\hline SW620 & 2.6 & 6.7 & 4.1 & 1.50 \\
\hline HCC2998 & 3.4 & 4.3 & 0.9 & 0.26 \\
\hline HCT116 p53 & 2.5 & 6.1 & 3.6 & 1.44 \\
\hline HCT116 p53\% & 1.5 & 2.3 & 0.8 & 0.44 \\
\hline $\mathrm{H} 460$ & 1.8 & 17.1 & 15.3 & 8.50 \\
\hline U87-MG & 12.85 & 21.26 & 8.41 & 0.65 \\
\hline MAC15A & 1.57 & 4.04 & 2.47 & 1.57 \\
\hline $\mathrm{MAC} 16$ & 10.64 & 11.34 & 0.70 & 0.06 \\
\hline MAC26 & 1.97 & 5.45 & 3.48 & 1.77 \\
\hline MAC29 & 2 & 3.2 & 1.2 & 0.60 \\
\hline MAC30 & 3.87 & 4.24 & 0.37 & 0.09 \\
\hline \multicolumn{5}{|l|}{ 5-fluorouracil } \\
\hline DLD-1 & 8.2 & 9.2 & 1.0 & 0.04 \\
\hline SW620 & 2.55 & 2.68 & 0.13 & 0.05 \\
\hline HCC2998 & 3.81 & 7.03 & 3.22 & 0.84 \\
\hline HCT116 p53+/+ & 3.5 & 8.5 & 5.0 & 1.38 \\
\hline HCT116 p53\% & 3.4 & 4.5 & 0.9 & 0.27 \\
\hline $\mathrm{H} 460$ & 4.7 & 6.17 & 1.47 & 0.31 \\
\hline U87-MG & 12.85 & 14.85 & 2 & .13 \\
\hline MAC15A & 2.44 & 7.4 & 4.96 & 2.03 \\
\hline MAC16 & 3.5 & 4.3 & 0.8 & 0.01 \\
\hline MAC26 & 3.3 & 7.1 & 3.8 & 1.15 \\
\hline MAC29 & 5.8 & 6.1 & 0.3 & 0.05 \\
\hline MAC30 & 4.8 & 8.5 & 3.7 & 0.77 \\
\hline \multicolumn{5}{|l|}{ Cisplatin } \\
\hline DLD-1 & 4.9 & 6.9 & 2 & 0.40 \\
\hline SW620 & 2.6 & 4.7 & 2.1 & 0.81 \\
\hline HCC2998 & 3.4 & 6.0 & 2.6 & 0.77 \\
\hline HCT116 p53+/+ & 4.2 & 5.3 & 1.1 & 0.26 \\
\hline HCT 116 p53\% & 5.2 & 5.5 & 0.3 & 0.05 \\
\hline $\mathrm{H} 460$ & 1.8 & 3.6 & 1.8 & 1.00 \\
\hline U87-MG & 12.85 & 16.9 & 4 & 0.23 \\
\hline MAC $15 A$ & 2.4 & 6.6 & 2.2 & 0.91 \\
\hline MAC16 & 4 & 9 & 5 & 1.5 \\
\hline MAC26 & 3.3 & 11.7 & 8.4 & 2.54 \\
\hline MAC29 & 2 & 11.5 & 9.5 & 4.75 \\
\hline MAC30 & 4.8 & 12.1 & 7.3 & 1.52 \\
\hline F9 & 1.42 & 7.93 & 6.5 & 5.09 \\
\hline
\end{tabular}

into wild-type and mutant groups (Table II and Fig. 4). The median SGD for doxorubicin and 5-fluorouracil was significantly longer in the wild-type groups of tumours than in the mutant group giving Mann-Whitney $U$ test value of $<0.05$, Table IV. Cisplatin did not produce a significantly longer SGD in either group being equally active against both groups of tumours $(>0.05)$, Table IV.

Staining for p53 in treated tumours. The HCT116 p53+/+ tumour was used to monitor the effect of doxorubicin within 
A
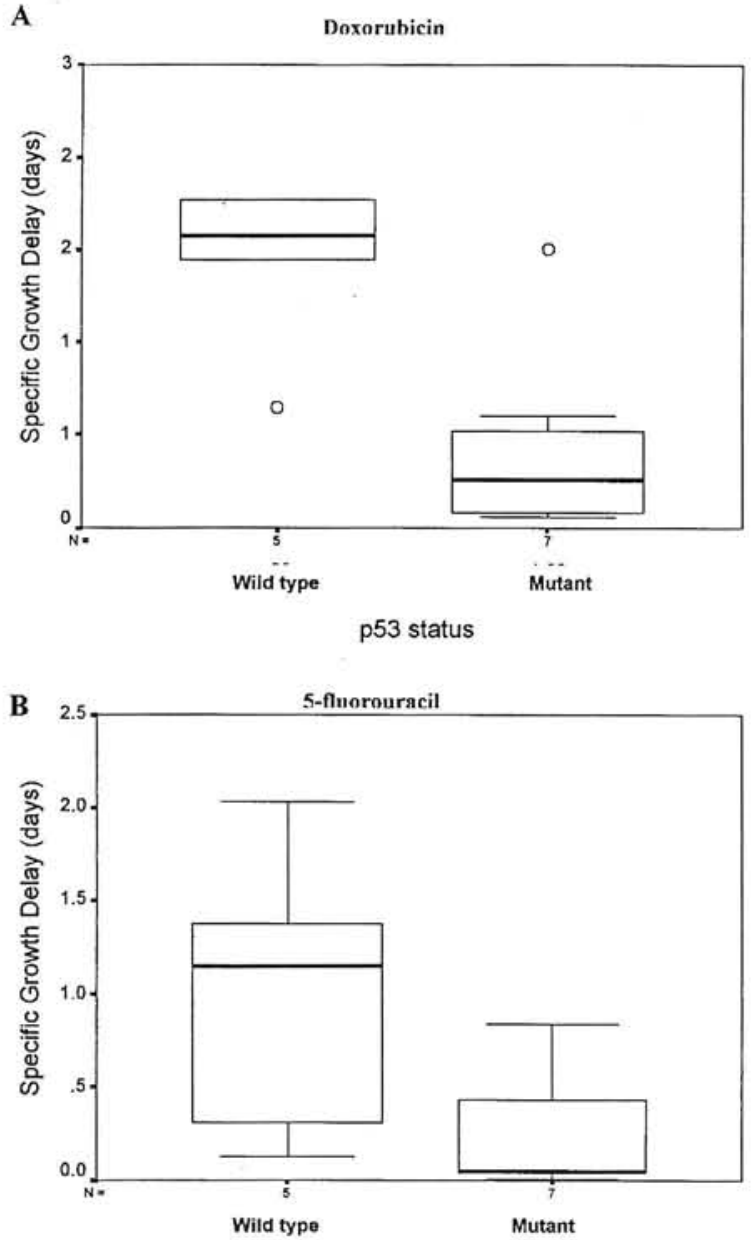

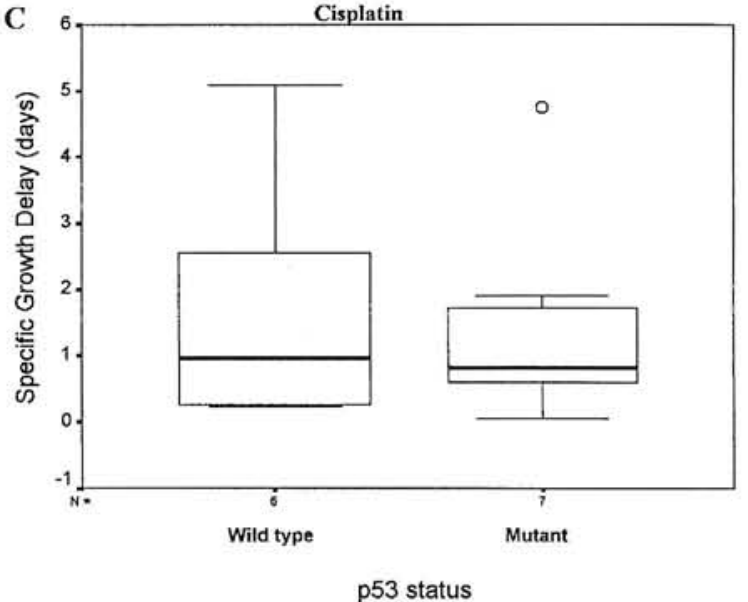

p53 status

Figure 4. Boxplots showing the mean specific growth delays for each of the tumours tested separated into two groups, wild-type and mutant p53 status. Bars represent the median of the values. Box represents the upper and lower $25 \%$ quartiles. Outliers are shown (0). Figures represent data from $6-12$ individual tumours for each type.

Table IV. Results of the Mann-Whitney U test for non-parametric analysis of the mean specific growth rates for wild-type p53 versus mutant $\mathrm{p} 53$ tumours.

\begin{tabular}{lccc}
\hline Agent & $\begin{array}{c}\text { Mean specific growth } \\
\text { delay (days) for wild-type } \\
\text { tumours }\end{array}$ & $\begin{array}{c}\text { Mean specific growth } \\
\text { delay (days) for mutant } \\
\text { tumours }\end{array}$ & $\begin{array}{c}\text { P-value from } \\
\text { Mann-Whitney } \\
\text { test }\end{array}$ \\
\hline Doxorubicin & $2.78 \pm 3.2$ & $0.43 \pm 0.40$ & $<0.05^{\mathrm{a}}$ \\
5-fluorouracil & $1.00 \pm 0.70$ & $0.26 \pm 0.30$ & $<0.05^{\mathrm{a}}$ \\
Cisplatin & $1.67 \pm 1.60$ & $1.40 \pm 1.57$ & $>0.05$ \\
\hline
\end{tabular}

${ }^{a}$ indicates significant difference.

the tumours. Treated tumours were excised at $12 \mathrm{~h}$ intervals and then $\mathrm{p} 53$ was detected on tumour sections. An upregulation of $\mathrm{p} 53$ was observed at around $24 \mathrm{~h}$ post treatment. The pattern of p53 staining, however, was not uniform throughout the tumour. Small tumour nodules showed an even distribution of cell nuclei staining for p53 across the section (Fig. 1E), but larger tumours showed a region of cells surrounding the necrotic centre which did not stain for p53 (Fig. 1F).

\section{Discussion}

This study reports the p53 status of a panel of tumour models used in drug discovery and their responsiveness to three standard agents in vivo. Assessment of basal p53 protein levels within the tumours was determined by two immunodetection methods, staining and Western blotting. Both methods gave similar results. Fifteen out of 25 tumours 
showed overexpression of $\mathrm{p} 53$. The yeast assay provided a means of assaying the functionality of the p53 cDNA from the tumour panel. Fourteen out of 25 tumours possessed cDNA that encoded for non-functional p53 protein, and these were included in the $15 / 25$ found to overexpress p 53 protein. One tumour overexpressing p 53 protein showed a heterozygous genotype. The HCT116 p53\% tumour had no gene (or cDNA) for $\mathrm{p} 53$ to assay and showed no p53 protein as expected. The HCC2998 tumour showed no p53 protein upon immunodetection but showed conflictingly non-functional p53 genes in the assay, indicating the possibility of a silencing, or a stop mutation. Indeed this cell line was classified as possessing a $213 R / S T O P$ mutation by the NCI (16). The remainder of the tumours possessed functional p53.

The immunodetection methodologies and the F.A.S.A.Y. analysis show, in this sample of tumours, that the tumours with p53 protein overexpression are indeed of mutant p53 status. However, the study also showed that not all tumours with low or undetectable p53 had wild-type p53 status. Therefore, immunodetection alone was not sufficient for the full analysis of p53 status, and must be coupled to a functional assay or sequencing protocol to be completely accurate.

It should be noted that many other pathways exist that can influence wild-type p53 activity within the cell. Mdm5 protein acts to inhibit p53 activity and is overexpressed in certain cancers, but these are rare and are not frequently found in the tissue types of the tumours studied here. In fact MDM5 overexpression was not found in any of the tumours studied (data not shown). The authors acknowledge that the Arf protein also modulates p53 activity but has not been studied in this panel of tumours. Also the panel of tumours tested were of known primary source which were known not to be associated with viral oncogenesis.

Our aim was to determine whether the p53 status of the tumours was an important factor in the sensitivity and response to the standard anti-tumour agents 5-fluorouracil, doxorubicin and cisplatin. These agents are clinically relevant and influence DNA, through various mechanisms. DNA damaging mechanisms may require or may activate a p53 pathway within the cells. The p53 tumour suppressor has been shown to modulate the effects of many cytotoxic agents including 5-fluorouracil (37), and doxorubicin (38) whereas the effect of p53 on cisplatin activity is ambiguous and remains to be fully elucidated. One would therefore expect these agents to exhibit a better anti-tumour activity towards the wild-type tumours rather than the mutant tumours. This was indeed the case for doxorubicin and 5-fluorouracil but was not the case for cisplatin. Cisplatin showed an equal activity towards wild-type and mutant cell lines. The specific growth delay obtained with cisplatin was as long as that obtained in the wild-type tumours with doxorubicin and 5fluorouracil, and was longer than that obtained from the mutant groups with these agents. This may indicate that doxorubicin and 5-fluorouracil may require wild-type p53 for activity, whereas cisplatin may not. The apparent sensitivity of some colon tumours (with mutant p53) to cisplatin treatment e.g. MAC29, was surprising given that many of them were very resistant to doxorubicin (sensitivities being similar to that of the testicular tumour F9). However, some colon tumours with wild-type p53 showed resistance to cisplatin. These data would indicate a common, non-wtp53, cisplatin-sensitivity marker in these tumours, which could warrant further study.

These results may indicate that p53 has no role in coordinating the response of tumours to cisplatin. The mechanism of action of cisplatin is associated with components of the mismatch repair pathway and microsatellite instability (39). However, the role of p53 in modulating various elements of the DNA repair pathways has not been fully elucidated either. The p53 tumour suppressor is thought to modulate the activities and timing of the DNA repair response for example the nucleotide excision repair pathway (40) and the global and transcription-coupled repair pathways $(41,42)$. Therefore, the role of p53 in the mechanism of cisplatin activity may be more subtle. Also, p53-mediated sensitivity to cisplatin may be cell-type specific. Some cells may undergo apoptosis in response to $\mathrm{p} 53$ induction whereas others may undergo cell cycle arrest. Cisplatin sensitivity has been observed in cell types not inherently prone to p53-mediated apoptosis when they have been disrupted for p53 function $(43,44)$.

In this study, 2 of the tumours represented a pair of isogenic cell lines HCT116 p53 $3^{+/+}$and HCT116 p53\% obtained from Dr B. Vogelstein, Baltimore, USA. The wild-type cell line HCT116 $\mathrm{p}^{53^{+/+}}$showed a better response and longer specific growth delay with the agents doxorubicin and 5fluorouracil, but both cell lines were resistant to cisplatin. The results seen with the p53 isogenic pair of cell lines reflected the general pattern seen in the whole panel of tumours.

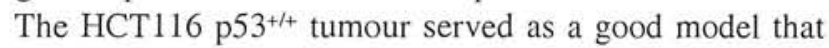
highlights the problems associated with chemotherapy and predicting treatment outcome. This tumour being wild-type for $\mathrm{p} 53$ initially showed a good response to doxorubicin with tumour growth being significantly slower than the isogenic tumour HCT $116 \mathrm{p} 53 \%$. The amount of cells staining for $\mathrm{p} 53$ is also maximal at this time. However, the p53 staining of treated tumours shows that doxorubicin has had no effect on the cells towards the centre of the tumour, in those cells surrounding the necrotic centre. This could be due to several reasons e.g. poor vascular supply/drug delivery, high interstitial pressure, less percentage of cycling cells etc. These are the population of cells which could be responsible for the regrowth of the tumour once the drug has been cleared, a situation very likely to be encountered in the clinic.

Future work in this field would include the closer examination of the treated tumours themselves. The in vivo growth study used here cannot differentiate whether the cells within the tumours are undergoing cytotoxicity by apoptosis or necrosis, or are merely undergoing growth arrest and repair. Further histological analysis should therefore be undertaken.

One would expect the inactivation of a protein with such a complex variety of functions within the cell, such as $\mathrm{p} 53$, to associate with a strong resistance to anti-tumour agents and the detection of mutations within patient tumours to strongly correlate with poor outcome to chemotherapy. Although some studies have shown such correlations, many have not or have not proved p53 to be a clinically useful marker, reviewed in (15). The correlations found in vitro reflect the relative simplicity of that setting, and accounts for the strong correlations found, but they do not mirror the more complex clinical setting, especially the three-dimensional nature of the drug-tumour interaction. The tumour models used in this 
study mirror the clinical setting much more closely, and they have shown themselves to be a useful system in determining how the properties and function of one gene/protein, namely p53 does have an effect on how these tumours respond. However, the correlations found here show that the p53 tumour suppressor seems to co-ordinate the response of tumours to some agents and not others. Although the extent of control over the variables in this study may not be possible in the clinic e.g. dosing times etc. These results indicate that p53 status can be useful as a prognostic or predictive marker, for the use of 5-fluorouracil and doxorubicin. The majority of the tumours used here were of colon origin, and the apparent lack of activity of 5-fluorouracil and doxorubicin against the group of tumours with mutant p53, suggests that their usefulness within the clinic may be limited to the wild-type tumours. Wild-type tumours showed a wide variation in responsiveness within this panel towards 5-fluorouracil and doxorubicin, however the mutant tumours showed a much reduced response with a narrow range of variation. Therefore, with regard to clinical decision making, it is likely that p53 would be more useful as an indicator of which tumours will not respond to a particular form of therapy, rather than being a prognostic marker. The results shown here are only relevant to primary tumours or large single metastatic deposits, not to small widely distributed metastasis. Therefore, these results cannot act as a prognostic indicator as the tumours used do not mirror the progression of the disease within a patient, they are a prognostic marker for a one tumour system. Although future work could bring in a more complex mouse-oriented tumour metastasis model.

In conclusion, this study describes the p53 status of tumours used in drug development and the different role the p53 tumour suppressor has in modulating the sensitivities of these tumours to different chemotherapy agents. Not only will these results be useful in investigating the role of p53 status on in vivo response to novel agents, but they may be useful in the detection and development of agents with novel non-DNA damaging (non-p53) activities, reducing the use of DNA damaging agents that eventually select for p53 mutations.

The status of tumour biopsies could be fully characterised for their p53 status by the techniques utilised in this study at time of diagnosis and throughout course of the disease, and the responsiveness of the tumours to various forms of therapy could be followed. In this way better use will be made of molecular profiling of tumours to aid in clinical decision making.

\section{Acknowledgements}

The authors acknowledge support from Cancer Research UK (Grants: C459/A2579 and C459/A2580). Advice on statistical analysis was given by Dr. David Jerwood, University of Bradford.

\section{References}

1. Levine AJ: p53, the cellular gatekeeper for growth and division. Cell 88: 323-331,1997.

2. Kastan MB, Onyekwere O, Sidransky D, Vogelstein B, and Craig RW: Participation of $\mathrm{p} 53$ protein in the cellular response to DNA damage. Cancer Res 51: 6304-6311, 1991.
3. Kuerbitz SJ, Plunkett BS, Walsh WV and Kastan MB: Wildtype p53 is a cell cycle checkpoint determinant following irradiation. Proc Natl Acad Sci USA 89: 7491-7495 1992.

4. El-Deiry WS, Harper JW, O'Connor PM, Velculescu VE, Canman CE, Jackman J, Pietenpol JA, Burrell M, Hill DE and Wang Y: WAF1/CIP1 is induced in p53-mediated G1 arrest and apoptosis. Cancer Res 54: 1169-1174, 1994.

5. Park JR and Hockenberg DM: BCL-2, a novel regulator of apoptosis. J Cell Biochem 60: 12-17, 1996.

6. Bennett M, Macdonald K, Chan SW, Luzio J P, Simari R and Weissberg P: Cell surface trafficking of Fas: a rapid mechanism of p53-mediated apoptosis. Science 282: 290-293, 1998.

7. Polyak K, Xia Y, Zweier JL, Kinzler KW and Vogelstein B: A model for p53-induced apoptosis. Nature 389: 300-305, 1997.

8. Lane DP: p53, guardian of the genome. Nature 358: 15-16, 1992.

9. Hollstein M, Sidransky D, Vogelstein B and Harris CC: p53 mutations in human cancers. Science 253: 49-53, 1991.

10. Reich NC and Levine AJ: Growth regulation of a cellular tumour antigen, p53, in nontransformed cells. Nature 308: 199$201,1984$.

11. Hall PA, Dowell SP and Lane DP: Tumor diagnosis. Nature 369: 701, 1994.

12. Ishioka C, Frebourg T, Yan YX, Vidal M, Friend SH, Schmidt S and Iggo R: Screening patients for heterozygous p53 mutations using a functional assay in yeast. Nat Genet 5: 124-129, 1993.

13. Flaman JM, Frebourg T, Moreau V, Charbonnier F, Martin C, Chappuis P, Sappino AP, Limacher IM, Bron L and Benhattar J: A simple p53 functional assay for screening cell lines, blood, and tumors. Proc Natl Acad Sci USA 92: 3963-3967, 1995.

14. Tada M, Iggo RD, Ishii N, Shinohe Y, Sakuma S, Estreicher A, Sawamura $\mathrm{Y}$ and $\mathrm{Abe} \mathrm{H}$ : Clonality and stability of the $\mathrm{p} 53$ gene in human astrocytic tumor cells: quantitative analysis of p53 gene mutations by yeast functional assay. Int J Cancer 67: 447-450, 1996.

15. Elledge RM and Allred DC: Prognostic and predictive value of p53 and p21 in breast cancer. Breast Cancer Res Treat 52: 79-98, 1998.

16. O'Connor PM, Jackman J, Bae I, Myers TG, Fan S, Mutoh M, Scudiero DA, Monks A, Sausville EA, Weinstein JN, Friend S, Fornace AJ Jr and Kohn KW: Characterization of the p53 tumor suppressor pathway in cell lines of the National Cancer Institute anticancer drug screen and correlations with the growthinhibitory potency of 123 anticancer agents. Cancer Res 57: 4285-4300, 1997.

17. Workman P, Twentyman P, Balkwill F, Balmain A, Chaplin D, Double J, Embleton J, Newell D, Raymond R, Stables J, Stephens T and Wallace J: United Kingdom co-ordinating committee on cancer research (UKCCCR): guidelines for the welfare of animals in experimental neoplasia (2nd edition). Br J Cancer 77: 1-10, 1998.

18. Berstine EG, Hooper ML, Grandchamp S and Ephrussi B: Alkaline phosphatase activity in mouse teratoma. Proc Natl Acad Sci USA 70: 3899-3903, 1973.

19. Double JA, Ball CR and Cowen PN: Transplantation of adenocarcinomas of the colon in mice. J Natl Cancer Inst 54: 271-275, 1975.

20. Double JA and Cifuentes de Castro L: Chemotherapy of transplantable adenocarcinomas of the colon in mice II, development and characterisation of an ascitic cell line. Cancer Treat Rep 62: 85-90, 1978.

21. Cowen DM, Double JA and Cowen PN: Some biological characteristics of transplantable lines of mouse adenocarcinomas of the colon. J Natl Cancer Inst 64: 675-681,1980.

22. Double JA and Bibby MC: Characterisation and chemosensitivity of a well-differentiated murine transplantable adenocarcinoma of the colon. Br J Cancer 48: 739-742, 1983.

23. Semple TU, Quinn LA, Woods LK and Moore GE: Tumor and lymphoid cell lines from a patient with carcinoma of the colon for a cytotoxicity model. Cancer Res 38: 1345-1355, 1978.

24. Dexter DL, Barbosa JA and Calabresi P: N,N-dimethylformamide-induced alteration of cell culture characteristics and loss of tumorigenicity in cultured human colon carcinoma cells. Cancer Res 39: 1020-1025, 1979.

25. Fogh J and Trempe G: New human tumour cell lines. In: Human Tumour Cell In Vitro. J. Fogh (ed). Plenum Press, New York, pp115-160, 1975.

26. Brattain MG, Fine WD, Khaled FM, Thompson J and Brattain DE: Heterogeneity of malignant cells from a human colonic carcinoma. Cancer Res 41: 1751-1756, 1981. 
27. Bunz F, Hwang PM, Torrance C, Waldman T, Zhang Y, Dillehay L, Williams J, Lengauer C, Kinzler KW and Vogelstein B: Disruption of p53 in human cancer cells alters the responses to therapeutic agents. J Clin Invest 104: 263-269, 1999.

28. Leibovitz A, Stinson JC, McCombs WB, McCoy CE, Maxur KC and Mabry ND: Classification of human colorectal adenocarcinoma cell lines. Cancer Res 36: 4562-4569, 1976.

29. Carney DN, Gazdar AF, Bepler G, Guccion JG, Marangos PJ, Moody TW, Zweig MH and Minna JD: Establishment and identification of small cell lung cancer cell lines having classic and variant features. Cancer Res 45: 2913-2923, 1985.

30. Naundorf H, Rewasowa EC, Fichtner I, Butter B, Becker M and Gorlich M: Characterisation of two human mammary carcinomas, MT-1 and MT-3, suitable for in vivo testing of ether lipids and their derivatives. Breast Cancer Res Treat 23: 87-95, 1992.

31. Soule HD, Vazguez J, Long A, Albert S and Brennan M: A human cell line from a pleural effusion derived from a breast carcinoma. J Natl Cancer Inst 51: 1409-1416, 1973.

32. Cailleau R, Young R, Olive M and Reeves WJ Jr: Breast tumour cell lines from pleural effusions. J Natl Cancer Inst 53: 661-674, 1974.

33. Cailleau $\mathrm{R}$, Olive $\mathrm{M}$ and Cruciger QVJ: Long term human breast carcinoma cell lines of metastatic origin: preliminary characterisation. In Vitro 14: 911-915, 1978

34. Ponten $\mathrm{J}$ and Macintyre EH: Interaction between normal and transformed bovine fibroblasts in culture. II. Cells transformed by polyoma virus. J Cell Sci 3: 603-613, 1968 .

35. Giard DJ, Aaronson SA, Todaro GJ, Arnstein P, Kersey JH, Dosik $\mathrm{H}$ and Parks WP: In vitro cultivation of human tumors: establishment of cell lines derived from a series of solid tumors. J Natl Cancer Inst 51: 1417-1423, 1973.

36. Steel GG, Courteney VD and Peckham MJ: The response to chemotherapy of a variety of human tumour xenografts. Br J Cancer 47: 3-13, 1983.
37. Yang B, Eshleman JR, Berger NA and Markowitz SD: Wild-type p53 protein potentiates cytotoxicity of therapeutic agents in human colon carcinoma cells. Clin Cancer Res 2: 1649-1657, 1996.

38. Tewey KM, Chen GL, Nelson EM and Liu LF: Intercalative antitumour drugs interfere with the breakage-reunion reaction of mammalian DNA topoisomerase II. J Biol Chem 259: 9182-9187, 1984.

39. Aebi S, Kurdi-Haidar B, Gordon R, Cenni B, Zheng H, Fink D, Christen RD, Boland CR, Koi M, Fishel R and Howell SB: Loss of DNA mismatch repair in acquired resistance to cisplatin. Cancer Res 56: 3087-3090, 1996.

40. Wang XW, Forrester K, Yeh H, Feitelson MA, Gu JR and Harris CC: Hepatitis B virus X protein inhibits p53 sequencespecific DNA binding, transcriptional activity, and association with transcription factor ERCC3. Proc Natl Acad Sci USA 91: 2230-2234, 1994.

41. Ford JM and Hanawalt PC: Li-Fraumeni syndrome fibroblasts homozygous for $\mathrm{p} 53$ mutations are deficient in global DNA repair but exhibit normal transcription-coupled repair and enhanced UV resistance. Proc Natl Acad Sci USA 92: 88768880,1995 .

42. Ford JM and Hanawalt PC: Expression of wild-type p53 is required for efficient global genomic nucleotide excision repair in UV-irradiated human fibroblasts. J Biol Chem 272: 2807328080, 1997.

43. Fan S, Smith ML, Rivet DJ II, Duba D, Zhan Q, Kohn KW, Fornace AJ Jr and O'Connor PM: Disruption of p53 function sensitizes breast cancer MCF-7 cells to cisplatin and pentoxifylline. Cancer Res 55: 1649-1654, 1995.

44. Fan S, Chang JK, Smith ML, Duba D, Fornace AJ Jr and O'Connor PM: Cells lacking CIP1/WAF1 genes exhibit preferential sensitivity to cisplatin and nitrogen mustard. Oncogene 14: 2127-36, 1997. 